\title{
Virtual Reality Heights Exposure and Its Impact on College Student's Physiological Response and Emotional Condition
}

\author{
Brilianda Resibisma ${ }^{1}$, Neila Ramdhani ${ }^{2}$ \\ Faculty of Psychology, Universitas Gadjah Mada \\ Submitted 16 March 2020 Accepted 12 May $2020 \quad$ Published 28 October 2020
}

\begin{abstract}
Various studies have been done to overcome excessive fear of heights. One way to overcome excessive fear of heights is to use exposure therapy. This study aimed to determine the effect of virtual reality heights exposure on physiological response and emotional condition in college students. The hypothesis of this study was that there is a significant effect of virtual reality heights exposure on physiological response and emotional condition that is characterized by changes in skin conductance when the stimulus is presented and changes in emotional condition after the stimulus is presented. The design applied in this study was a non-random pretest and posttest experiment. The results of this study indicated that there is a significant influence of virtual reality exposure on physiological response and emotional condition. Thus, the finding opens up opportunities for therapy using this method in Indonesia.
\end{abstract}

Keywords: emotional condition; height; physiological response; virtual reality exposure

Excessive and irrational fear is often experienced by individuals, especially excessive fear (phobia) of heights. Many studies had been done to find resolve to this issue. One of the methods to subdue fear of heights is by using exposure therapy.

Exposure therapy is a therapy designed according to behavioural approach done by exposing client to feared stimulus systematically and repeatedly in certain situations, whether in vivo or through imagination (American Psychological Association, 2015). Exposure therapy method usually applied to deal with excessive fear of heights is in vivo

Adress for correspondence:

brillianda.resibisma@mail.ugm.ac.id
(Li \& World Scientific and Engineering Academy and Society, 2008). The method is done by presenting subject with stimulus realistically, such as by climbing stairs in multi-storey buildings. Another approach done is by applying in vivo exposure through virtual reality $(\mathrm{Li} \&$ World Scientific and Engineering Academy and Society, 2008).

In vivo exposure through virtual reality was first studied by Rothbaum and his colleagues in 1955 and was named Virtual Reality Graded Exposure (VRGE) (Weir, 2018). Today, in vivo exposure through virtual reality has been studied extensively. One popular topic is the effectiveness of virtual reality exposure to reduce anxiety and avoidant of heights (Emmelkamp, Bruynzeel, Drost, \& van der 
Mast, 2001; Gorini et al., 2009; Parsons \& Rizzo, 2008; Rothbaum et al., 1995).

Meanwhile, a study about virtual reality exposure done in Indonesia had shown that the method can reduce acrophobia' fear of heights and such fear among general public (Suyanto, Angkasa, Turaga, \& Sutoyo, 2017). However, study of virtual reality exposure that involves physiological aspects and emotional conditions had not been done prior to this study in Indonesia. It is important to study those two aspects to see if the 3-D environment shown through virtual reality can affect individual, determined through physiological responses and emotional conditions, so that this therapy method can be applied in Indonesia. If virtual reality exposure can influence physiological responses and emotional conditions, then the opportunity of incorporating this therapy method in Indonesia would be bigger.

Exposure is one of the methods that can be used in treating phobia. Exposure is done by presenting stimulus usually avoided by the individual so that they have to face it. However, this is often difficult to exercise in real life because the individual is incapable of facing such stimulus directly, so another method of stimulus exposure was introduced. This method is done by presenting feared stimulus virtually. It is done within virtual reality environment thus it is often called virtual reality exposure (Mühlberger, Herrmann, Wiedemann, Ellgring, \& Pauli, 2001).

Due to two main characteristics of virtual reality, namely presence and immersion, the virtual environment created feels very realistic (Slater, Lotto, Arnold, \&
Sanchez-Vives, 2009; Witmer \& Singer, 1998). Presence is a short term for telepresence (International Society for Presence Research, 2000). Telepresence is the feeling incited when someone who is in a secluded place is given sensory information from a remote location using modern communication technology (APA, 2015). It means that an individual feels like $\mathrm{s} /$ he is present in one place even if actually the person knows s/he is not in there. The feeling of being present at a certain place occurs because sensory information received by individual through messages sent within the virtual environment supported by VR technology. According to Sanchez-Vives and Slater (2005), presence can be defined as individual's tendency to respond to sensory data produced virtually, as if they were real. Presence can be measured, where objectively (e.g., heartbeat rate or body posture) or subjectively (questionnaire) (Krijn, Emmelkamp, Olafsson, \& Biemond, 2004). Generally, presence is measured using questionnaire. Immersion is a psychological condition marked by self-perception to be present, included, or to interact in an environment that provides streamlined and sustainable stimuli and experiences (Witmer \& Singer, 1998). The higher immersion level created by virtual environment, the higher presence level felt by an individual (Witmer \& Singer, 1998). If an individual is presented with feared stimulus through virtual reality, the person will feel that the situation is real because there is sensory information received. At this stage, sympathetic nervous system will be active and work to detect the signs of danger (Kalat \& Shiota, 2011). One 
of the effects that may occur is increased secretion of sweat glands.

Virtual reality exposure has been extensively researched in relation to physiological responses and emotional conditions. A study showed that the percentage of heart rate change and skin elasticity have high correlation to the level of realism and immersion of virtual reality exposure (Wiederhold et al., 2001). Studies on physiological responses and emotional conditions revealed significant towards virtual reality (Gorini et al., 2009; Kotlyar et al., 2008; Parsons \& Rizzo, 2008). However, study on virtual reality exposure's effect on physiological responses and emotional conditions in Indonesian context, particularly college students, had yet been done. This rises opportunities for more virtual reality exposure studies in Indonesia. College students were chosen as subjects because they are included in emerging adult category. According study by Rosa and colleagues (2016), individual in emerging adulthood has higher tendency for immersion if compared to middle and late adulthoods. Higher immersion tendency makes it easier to see the influence of virtual reality exposure on physiological responses and emotional conditions.

Based on explanation above, researchers formulated a hypothesis that there is a significant influence of virtual reality exposure on physiological responses and emotional conditions marked by different emotional and physiological responses on the skin after receiving virtual reality heights exposure. There would be an increase of skin reaction when an individual is on elevated surface than when s/he not.

\section{Method}

Variables studied in this research were virtual reality exposure, physiological response, and emotional condition. Dependent variables in this study were physiological response and emotional condition while virtual reality exposure was the independent variable. Method used in the study was non-random pre-test and post-test experiment.

\section{Subjects}

Subjects were 106 college students, 34 male students and 72 female students. Research subjects were students from various faculties of universities located in Yogyakarta Province. The age range of the subjects was 19 to 27 years old. Subjects included in the analysis were the ones who finished all the study stages well.

\section{Study procedures}

The first step of this study was subject recruitment process which was done online according to specified criteria. Then, subjects were asked to sign informed consents. Prior to the experiment, subjects were given pretest to measure responses of emotional condition (APQ Pre). Each subject was asked to go to a small platform prepared and hold onto a handrail. At that time, the skin conductance (SC1) measure was done. Then the subject was given headmounted display (HMD). After subject was deemed ready, s/he was requested to stay calm while physiological response (SC2) measure was conducted. Subject was then 
brought to the upper part of building using elevator in virtual environment while skin conductance (SC3) measure was taken. Subject was also requested to look at the surroundings at the time measure of physiological response (SC4) was done. After those measurements were done, HMD would be removed. That was when the last skin conductance (SC5) assessment was taken. Subjects who felt uncomfortable due to the data collection process were provided psychological service for aid. Lastly, subjects were presented with posttest (APQ Post) which was similar to the pretest. Subjects who completed the entire experiment stages received rewards.

\section{Instruments}

Virtual reality environment used in the study was Richie's Plank Experience application developed by Toast from Steam platform (Toast, 2017). The use of this application in the study had been approved by the program developer. Stimulus presented is elevator in a storey building. When user is inside the elevator, they are brought to the upper floor of the 80-storeys building. In the upper floor, when the elevator door opens, user can see a plank measured at $1.5 \mathrm{~m} \times 30 \mathrm{~cm}$. The plank is suspended in the air but attached to the building. There are other stimuli present such as skyscrapers and trees underneath. Virtual reality environment was presented using Oculus Rift Development Kit 2, while software used was Oculus developed by Oculus and SteamVR which was developed by Valve. The computer specifications used to produce virtual reality stimuli in this study was similar to specifications used in a study by Ramdhani, Akpewila, Faizah, and
Resibisma (2019) which were Intel ${ }^{\circledR}$ Core $^{\mathrm{TM}}$ i5-7400 Processor (6M Cache, up to $3.50 \mathrm{GHz}$ ), graphic card Gigabyte NVIDIA GeForce ${ }^{\circledR}$ GTX 1060 Colourful Corsair VENGEANCE® RGB $\quad 16 G B \quad(2 \quad x \quad 8 G B)$ DDR4 DRAM $2666 \mathrm{MHz}$ C16 Memory Kit, HDD Seagate 1TB, SSD Seagate 120GB, and Windows 10 Education operation system. Supporting equipments utilized in this study were headphone FLECO FL-168BT, microphone Intopic JAZZ-012 Desktop Microphone, and electric fan.

Biofeedback applied in the study was ProComp5 Infiniti biofeedback system developed by Thought Technology Ltd. Sensor used was Skin Conductance (SC). SC is a sensor that works by detecting the number of active sweat glands. The skin conductance activity is directly related to the number of active sweat glands in one's finger and controlled by sympathetic nervous system (Jiang, Chang, \& Sullivan, 2014). Software used to calculate signal received by the sensor was BioGraph Infiniti Software V6.0 which was also developed by Thought Technology Ltd.

Autonomic Perception Questionnaire (APQ) is a scale developed by Mandler, Mandler, and Uviller (1958). APQ consists of 24 items aimed to measure selfawareness on bodily sensations such as heart rate, sweat level, change of temperature, breath, digestion, muscular strains, and blood pressure (Seinfeld dkk., 2016). According to Mandler (in Seinfeld et al., 2016), high APQ score indicates high awareness which correlates positively to anxiety responses, heart rate, and skin conductance. The APQ used in this study had response range from 1 to 7 and a version modified by University College 
London (UCL). The scale used had been translated into Bahasa Indonesia using back-translation technique. There were two translators involved; the first one translated this scale to target language while the second translator translated the first translation result back to its origin language (Brislin, 1970). Translation result from the second translator was then compared to the original version. If it is identical then the first translation result is considered representative to the original (Brislin, 1970).

\section{Data analysis}

Data analysis was done by comparing pretest and posttest of APQ and SC with paired T-test. Data was analyzed with the aid of IBM SPSS Statistics 23 Version. Hypothesis would be accepted if there was significant difference in pretest and posttest. On the contrary, hypothesis would be rejected if no significant difference was to be found.

\section{Results}

As seen in Table 1 and Table 2, in the measurement of skin conductance there was a significant mean difference between SC1 and SC2 (mean difference $=-0.45642 ; \mathrm{p}=0.00$, $\mathrm{p}<0.05)$. It showed that after wearing HMD and being presented with the stimulus of being inside an elevator, subject started to be aroused or stimulated. However, there were no significant differences found between genders and age groups. Then, significant mean difference was also found between SC2 and SC3 (mean $=-0.25915 ; \mathrm{p}=$ $0.00, p<0.05)$. It indicated that when being presented with stimulus of the elevator going up, subjects felt stimulated again. Another significant mean difference was also found between SC3 and SC4 (mean = 0.60217; $\mathrm{p}=0.00, \mathrm{p}<0.05)$. It meant that when stimulus of being at the top part of the building was presented, subjects felt aroused. The next measurement also showed significant score difference between SC4 and SC5 (mean $=0.30443 ; \mathrm{p}=$

Table 1.

Paired Samples T-Test Statistical Results

\begin{tabular}{clccc}
\hline \multirow{2}{*}{ Pair } & Mean & Standard Deviation & Standard Error Mean \\
& SC1 & 1.9607 & 1.55466 & 0.15100 \\
Pair & SC2 & 2.4171 & 1.74149 & 0.16915 \\
& SC2 & 2.4171 & 1.74149 & 0.16915 \\
& SC3 & 2.6762 & 2.07362 & 0.20141 \\
Pair & SC3 & 2.6762 & 2.07362 & 0.20141 \\
& SC4 & 3.2784 & 2.33115 & 0.22642 \\
\multirow{5}{*}{ Pair } & SC4 & 3.2784 & 2.33115 & 0.22642 \\
& SC5 & 2.9740 & 2.07474 & 0.20152 \\
& SC5 & 2.9740 & 2.07474 & 0.20152 \\
& SC1 & 1.9607 & 1.55466 & 0.15100 \\
& APQ Pre & 83.80 & 26.117 & 2.537 \\
& APQ Post & 67.62 & 26.600 & 2.584 \\
\hline
\end{tabular}


Table 2.

Paired Samples T-Test Analysis Results

\begin{tabular}{|c|c|c|c|c|c|c|}
\hline Pair & $\begin{array}{l}\text { Paired } \\
\text { Mean }\end{array}$ & $\begin{array}{c}\text { Std. } \\
\text { Deviation }\end{array}$ & $\begin{array}{c}\text { Std. Error } \\
\text { Mean }\end{array}$ & $t$ & $d f$ & $\begin{array}{l}\text { Sig. (2 } \\
\text { tailed) }\end{array}$ \\
\hline SC1 - SC2 & -0.45642 & 0.71920 & 0.06986 & -6.534 & 105 & 0.000 \\
\hline $\mathrm{SC} 2-\mathrm{SC} 3$ & -0.25915 & 0.56924 & 0.05529 & -4.687 & 105 & 0.000 \\
\hline SC3 - SC4 & -0.60217 & 0.62947 & 0.06114 & -9.849 & 105 & 0.000 \\
\hline SC4 - SC5 & 0.30443 & 0.47249 & 0.04589 & 6.634 & 105 & 0.000 \\
\hline SC5 - SC1 & 1.01330 & 0.89855 & 0.08728 & 11.610 & 105 & 0.000 \\
\hline $\begin{array}{l}\text { APQ Pre- } \\
\text { APQ Post }\end{array}$ & 16.179 & 24.550 & 2.385 & 6.785 & 105 & 0.000 \\
\hline \multicolumn{7}{|c|}{$\begin{array}{l}\text { APQ Post } \\
\text { 0.00, } \mathrm{p}<0.05 \text { ). This showed that after HMD } \\
\text { had been removed, the arousal level } \\
\text { decreased as well. However, seeing the } \\
\text { comparison between SC5 and SC1 (mean = } \\
\text { 1.01330; } \mathrm{p}=0.00, \mathrm{p}<0.05 \text { ), gairah subjek } \\
\text { setelah HMD dilepaskan masih lebih tinggi } \\
\text { dibandingkan pada pengukuran awal. } \\
\text { Meanwhile, APQ measurement also } \\
\text { revealed significant different in pretest and } \\
\text { posttest scores (mean = } 16.179 ; \mathrm{p}=0.00 \text {, p }< \\
0.05 \text { ). Taking a look at the mean scores it } \\
\text { was found that APQ Pre (mean }=83.80 \text { ) was } \\
\text { higher than APQ Post (mean }=67.62 \text { ). This } \\
\text { finding indicated that subject became less } \\
\text { aware of their bodily responses after } \\
\text { receiving stimuli which implied that the } \\
\text { anxiety dissipated. According to Table } 3 \\
\text { and Table 4, further study done by } \\
\text { researcher showed no significant difference }\end{array}$} \\
\hline \multicolumn{7}{|l|}{$\begin{array}{l}\text { Table } 3 \\
\text { Indepen }\end{array}$} \\
\hline & $\begin{array}{r}\text { Mea } \\
\text { Differ }\end{array}$ & $\begin{array}{r}\text { Std. E } \\
\text { Differ }\end{array}$ & & & & (2 tailed) \\
\hline SC1 & 0.213 & 0.343 & & 104 & & 0.513 \\
\hline SC2 & 0.212 & 0.363 & & 104 & & 0.561 \\
\hline SC3 & 0.402 & 0.431 & & 104 & & 0.353 \\
\hline SC4 & 0.441 & 0.485 & & 104 & & 0.365 \\
\hline SC5 & 0.335 & 0.432 & & 104 & & 0.439 \\
\hline APQ Pre & 10.3 & 5.3 & & 104 & & 0.057 \\
\hline APQ Post & -0.9 & 5.5 & -0 . & 104 & & 0.859 \\
\hline
\end{tabular}


Table 4

Results of One-way ANOVA Based on Age

\begin{tabular}{|c|c|c|c|c|}
\hline & & Mean Square & $\mathrm{df}$ & Sig. \\
\hline \multirow[t]{2}{*}{ SC1 } & Between groups & 1.641 & 4 & 0.614 \\
\hline & Within groups & 2.448 & 101 & \\
\hline \multirow[t]{2}{*}{ SC2 } & Between groups & 1.721 & 4 & 0.694 \\
\hline & Within groups & 3.085 & 101 & \\
\hline \multirow[t]{2}{*}{ SC3 } & Between groups & 1.920 & 4 & 0.782 \\
\hline & Within groups & 4.394 & 101 & \\
\hline \multirow[t]{2}{*}{ SC4 } & Between groups & 4.125 & 4 & 0.559 \\
\hline & Within groups & 5.486 & 101 & \\
\hline \multirow[t]{2}{*}{ SC5 } & Between groups & 3.634 & 4 & 0.504 \\
\hline & Within groups & 4.331 & 105 & \\
\hline \multirow[t]{2}{*}{ APQ Pre } & Between groups & 207.420 & 4 & 0.880 \\
\hline & Within groups & 700.883 & 101 & \\
\hline \multirow[t]{2}{*}{ APQ Post } & Between groups & 680.671 & 4 & 0.433 \\
\hline & Within groups & 708.616 & 101 & \\
\hline
\end{tabular}

\section{Discussion}

The finding obtained by researcher that virtual reality exposure affects physiological response and emotional condition which was shown by significant score differences in skin conductance and pre-posttest of APQ measures. It is aligned with the finding Seinfeld et al. (2016) which stated that there is a significant skin conductance effect in the higher ground, implying that an individual feels stimulated in such condition. However, significant difference in APQ Pre dan APQ Post measures showed that subjects did not feel anxious. According to Dobricki and Pauli (2016), that might have been caused by sensorimotor body-environment interaction (SBI). SBI is a component that helps brain to regulate environment's emotional experience and its exploration through head movement. Based on the concept of SBI, subjects were likely to perceive virtual environment presented as something positive and even fun (Dobricki \& Pauli, 2016). Further, Dobricki also Pauli (2016) explained that subjects perceived the virtual environment as something positive when being on an even surface (safe) if compared to when being on a high surface (unsafe). Generally, data that showed subjects did not feel anxious were perhaps obtained when subjects were in a place they deemed as safe (elevator), and not in an unsafe spot (wooden plank). This might be the reason why subjects perceived presented stimuli as something positive and felt stimulated by them.

Result of this study is also aligned with finding from Kotlyar et al. (2008) which proved that significant physiological response occurs due to virtual reality exposure. Another study conducted by Parsons and Rizzo (2008) is also aligned with present study's result. Parsons and Rizzo stated that virtual reality exposure 
induces significant effect in individual's affective domain. In addition, the study result is also similar to the one done by Gorini et al. (2009) which revealed that virtual reality exposure has significant calming effect. Based on these findings, it is possible to conduct further study on virtual reality exposure in Indonesia.

Meanwhile, further analysis showed no significant difference in physiological response and emotional condition between genders and ages. It is likely to be caused by limited range of ages studied, all of which grouped into emerging adult category. Moreover, the representation of subjects based on the genders was not balanced. This finding urges the necessity of further study that discusses age factor.

The limitation of this study is that it did not make comparison between people who have fear of heights and the ones who do not have. This study also did not consider other in-subject factors e.g., other phobias present in subjects, whether subjects had already used VR or 3D environment as applied in the study, and the immersion tendency in subjects. Moreover, this study did not include other physiological factors as measured entities. It is expected that future study to address these issues.

\section{Conclusion}

Based on the results of this research, it can be concluded that there is an effect of virtual reality heights exposure towards physiological response and emotional condition in college students. It promises opportunities to use virtual reality as therapy method in Indonesia. Immersion and presence which characterize virtual reality cause virtual reality exposure to be an alternative treatment in the case fear of heights.

\section{Suggestion}

Based the study that had been conducted, there are several suggestions from researcher for next studies, which is to consider several other subjective factors e.g., immersion tendency, anxiety of heights, and subjective state during pretest and posttest. The next studies should also involve measures of other physiological aspects e.g., heart rate, breathing, and body temperature. Meanwhile, according to the results of this research, further study of virtual reality exposure effects is needed within the context of virtual reality exposure therapy.

Author's note. This paper is a part of larger research named It's so Real: Psychophysiological Reaction towards Virtual Reality Exposure which was presented at International Conference on Science and Technology (ICST) in Yogyakarta, Indonesia on 30 - 31 July 2019.

\section{References}

American Psychological Association. (2015). APA dictionary of psychology (2nd edition). Washington: American Psychological Association. doi: https://doi.org/10.1037/14646-000

Brislin, R. W. (1970). Back-translation for cross-cultural research. Journal of Cross-Cultural Psychology, 1(3), 185216.

doi: 
https://doi.org/10.1177/135910457000 100301

Dobricki, M., \& Pauli, P. (2016). Sensorimotor body-environment interaction serves to regulate emotional experience and exploratory behavior. Heliyon, 2(10), e00173. doi: https://doi.org/10.1016/j.heliyon.201 $\underline{6 . \mathrm{e} 00173}$

Emmelkamp, P. M. G., Bruynzeel, M., Drost, L., \& van der Mast, C. A. P. G. (2001). Virtual reality treatment in acrophobia: A comparison with exposure in vivo. CyberPsychology $\mathcal{E}$ Behavior, 4(3), 335-339. doi: https://doi.org/10.1089/109493101300 210222

Gorini, A., Mosso, J. L., Mosso, D., Pineda, E., Ruíz, N. L., Ramíez, M., ... Riva, G. (2009). Emotional response to virtual reality exposure across different cultures: The role of the attribution process. CyberPsychology $\mathcal{E}$ Behavior, 12(6), 699-705. doi: https://doi.org/10.1089/cpb.2009.019 $\underline{2}$

International Society for Presence Research. (2000). Presence defined. Diakses melalui https://ispr.info/aboutpresence-2/about-presence/ (on 25 Januari 2019)

Jiang, B., Chang, C.-Y., \& Sullivan, W. C. (2014). A dose of nature: Tree cover, stress reduction, and gender differences. Landscape and Urban Planning, 132, 26-36. doi: https://doi.org/10.1016/j.landurbplan .2014 .08 .005
Kalat, J. W., \& Shiota, M. N. (2011). Emotion (2nd edition). Belmont, CA: Wadsworth Publishing.

Kotlyar, M., Donahue, C., Thuras, P., Kushner, M. G., O'Gorman, N., Smith, E. A., \& Adson, D. E. (2008). Physiological response to a speech stressor presented in a virtual reality environment. Psychophysiology, 45(6), 1034-1037.

doi:

https://doi.org/10.1111/j.1469-

8986.2008.00690.x

Krijn, M., Emmelkamp, P. M. G., Olafsson, R. P., \& Biemond, R. (2004). Virtual reality exposure therapy of anxiety disorders: A review. Clinical Psychology Review, 24(3), 259-281. doi:

https://doi.org/10.1016/j.cpr.2004.04. $\underline{001}$

Li, Q., \& World Scientific and Engineering Academy and Society (Ed.). (2008). Advances on applied computer $\mathcal{E}$ applied computational science: Proceedings of the 7 th WSEAS International Conference on Applied Computer \& Applied Computational Science (ACACOS '08): Hangzhou, China, April 6 - 8, 2008. Athen: WSEAS Press.

Mandler, G., Mandler, J. M., \& Uviller, E. T. (1958). Autonomic feedback: The perception of autonomic activity. Journal of Abnormal Psychology, 56(3), 367-373.

doi:

https://doi.org/10.1037/h0048083

Mühlberger, A., Herrmann, M. J., Wiedemann, G., Ellgring, H., \& Pauli, P. (2001). Repeated exposure of flight phobics to flights in virtual reality. Behaviour Research and 
Therapy, 39(9), 1033-1050. doi:

https://doi.org/10.1016/S0005-

7967(00)00076-0

Parsons, T. D., \& Rizzo, A. A. (2008).

Affective outcomes of virtual reality exposure therapy for anxiety and specific phobias: A meta-analysis. Journal of Behavior Therapy and Experimental Psychiatry, 39(3), 250261.

doi:

https://doi.org/10.1016/j.jbtep.2007.0 $\underline{7.007}$

Ramdhani, N., Akpewila, F., Faizah, M. \& Resibisma, B. (2019). It's so real: Psychophysiological reaction towards virtual reality exposure. 2019 5th International Conference on Science and Technology (ICST), 1, 1-5. https://doi.org/10.1109/ICST47872.20 19.9166212

Rosa, P. J., Morais, D., Gamito, P., Oliveira, J., \& Saraiva, T. (2016). The immersive virtual reality experience: A typology of users revealed through multiple correspondence analysis combined with cluster analysis technique. Cyberpsychology, Behavior, and Social Networking, 19(3), 209-216.

doi:

https://doi.org/10.1089/cyber.2015.01 $\underline{30}$

Rothbaum, B. O., Hodges, L. F., Kooper, R., Opdyke, D., Williford, J. S., \& North, M. (1995). Virtual reality graded exposure in the treatment of acrophobia: A case report. Behavior Therapy, 26(3), 547-554. doi: https://doi.org/10.1016/S0005-

$\underline{7894(05) 80100-5}$

Sanchez-Vives, M.V. \& Slater, M.. (2005). From presence to consciousness through virtual reality. Nature Reviews Neuroscience, 6, 332-339. doi: https://doi.org/10.1038/nrn1651

Seinfeld, S., Bergstrom, I., Pomes, A., Arroyo-Palacios, J., Vico, F., Slater, M., \& Sanchez-Vives, M. V. (2016). Influence of music on anxiety induced by fear of heights in virtual reality. Frontiers in Psychology, 6, 112.

doi:

https://doi.org/10.3389/fpsyg.2015.01 $\underline{969}$

Slater, M., Lotto, B., Arnold, M. M., \& Sanchez-Vives, M. V. (2009). How we experience immersive virtual environments: The concept of presence and its measurement. Anuario de Psicología, 40(2), 193-210.

Suyanto, E. M., Angkasa, D., Turaga, H., \& Sutoyo, R. (2017). Overcome acrophobia with the help of virtual reality and kinect technology. Procedia Computer Science, 116, 476483.

doi: https://doi.org/10.1016/j.procs.2017.1 $\underline{0.062}$

Toast. (2017). Richie's Plank Experience. Diakses dari https://store.steampowered.com/ap p/517160/Richies_Plank_Experience/ (pada 24 Februari 2019)

Weir, K. (2018). Virtual reality expands its reach. Monitor on Psychology, 49(2), 52-58. Diakses melalui https://www.apa.org/monitor/2018/ 02/virtual-reality

Wiederhold, B. K., Jang, D. P., Kaneda, M., Cabral, I.,..., Kim, S. I. (2001). An investigation into physiological responses in virtual environments: An objective measurement of 


\section{RESIBISMA \& RAMDHANI}

presence. Dalam G. Riva \& C. Galimberti (Eds), Towards cyberpsychology: Mind, cognitions and society in the internet age (pp. 175184). Amsterdam: IOS Press.

Witmer, B. G., \& Singer, M. J. (1998). Measuring presence in virtual environments: A presence questionnaire. Presence: Teleoperators and Virtual Environments, 7(3), 225240. doi: https://doi.org/10.1162/105474698565 $\underline{686}$ 